\title{
Physiological quality and seed respiration of primed Jatropha curcas seeds
}

\author{
Micheli Angelica Horbach ${ }^{*}$, João Alexandre Lopes Dranski ${ }^{1}$, Ubirajara Contro Malavasi \\ and Marlene de Matos Malavasi ${ }^{1}$
}

Received: June 12, 2017

Accepted: August 23, 2017

\begin{abstract}
Seed deterioration is a natural and irreversible process. Nevertheless, seed priming with water and antioxidants can minimize oxidative damage in oilseeds, resulting in attenuation of seed deterioration. The objective of this assay was to evaluate seed priming on respiratory activity of Jatropha curcas submitted to accelerated aging. Seeds from two provenances (Janauba and Pedro J. Caballero) were submitted to three priming treatments (control, immersion in deionized water, and with $750 \mu \mathrm{mol} \mathrm{L}{ }^{-1}$ of ascorbic acid) and treated for accelerated aging at $41{ }^{\circ} \mathrm{C}$ for $72 \mathrm{~h}$. The results showed that the priming of J. curcas seeds promoted tolerance to accelerated aging. Primed seeds, with ascorbic acid from Janauba and deionized water from Pedro J. Caballero, resulted in a higher percentage of normal seedlings, and increased germination speed index and seed respiration. The decline of physiological quality of J. curcas seeds after accelerated aging is directly associated with a reduction in respiratory activity that is related to seed moisture content.
\end{abstract}

Keywords: accelerated aging, ascorbic acid, gas chromatography, oil seeds, physic nut

\section{Introduction}

Jatropha curcas (Euphorbiaceae), commonly known as physic nut, is native to the American tropics and is used to produce biodiesel feedstock (Abhilash et al. 2011). The oil produced from its seeds has properties similar to those of fossil diesel. Nevertheless, more than $95 \%$ of the oil produced for biodiesel purposes comes from edible oils, which can have a negative impact on food production (Gui et al. 2008; Yunus Khan et al. 2014). The oil of J. curcas is non-edible due to toxic constituents of the seeds, as a consequence its exploitation does not compromise food production (Koh \& Ghazi 2011). Moreover, this plant exhibits drought tolerance and is easily cultivated (Costa et al. 2015).

Despite the fact that J. curcas grows abundantly in several areas, little is known about the lifespan of its seeds. Seed deterioration is a natural and irreversible process, even under ideal storage conditions. Dry seeds suffer a variety of biochemical and metabolic changes, including lipid peroxidation, enzyme inactivation and rupture of cellular membranes (Bewley et al. 2013).

Auto-oxidation of lipids and increased content of free fatty acids are the main reasons for rapid seed deterioration (Shaban 2013). An increase in total peroxide accumulation and in the content of malondialdehyde occurs in aged seeds, along with decreased activity of antioxidant enzymes (Goel et al. 2003). As a result, a reduction in enzyme content and activity decreases the respiratory capacity of seeds.

Mitochondria is the major site of synthesis and removal of reactive oxygen species and, moreover, of seed tolerance to oxidative stress (Bewley et al. 2013; Xin et al. 2014). Therefore, seed respiration and oxygen consumption are good indicators of the activation of germinative metabolic processes, and seeds with low levels of respiration do not

1 Programa de Pós-graduação em Agronomia, Universidade Estadual do Oeste do Paraná, 85960-000, Marechal Cândido Rondon, PR, Brazil

* Corresponding author: michelihorbach112@gmail.com 
germinate rapidly or completely (Patanè et al. 2006). Respiration and oxygen consumption are also useful for rapidly evaluating seed vigor in crops (Zhao \& Zhong 2012).

In addition, exogenous application of antioxidant enzymes improves plant stress tolerance and increases seed respiration rate and ATP synthesis, with a positive effect on seed germination (Zheng et al. 2009). The presence of antioxidants, such as ascorbic acid, help to prevent lipid peroxidation due to free radical scavenging (Goel et al. 2003; Brilhante et al. 2013). Treatment with ascorbic acid can also attenuate the deleterious effects of aging on cell membrane integrity and favor physiological seed quality (Brilhante et al. 2013).

Meanwhile, the immersion of seeds in water, or hydropriming, contributes to an increase in the ascorbic acid content of mitochondria and its involvement in the ascorbate-glutathione cycle, which is responsible for conferring increased tolerance to oxidative stress (Sun et al. 2011). Water priming also enables the restructuring and reorganization of the cell membrane system, and promotes cellular compartmentalization resulting in the attenuation of seed deterioration (Marcos Filho 2015).

Based on the above arguments, the assay of the present study aimed to evaluate the effects of priming on the physiological quality and respiratory activity of J. curcas seeds submitted to accelerated aging.

\section{Materials and methods}

Fruits of J. curcas were collected in September 2014, from adult plants of Janauba and Pedro Juan Caballero provenances, which grown in seed production areas (SPA) in the municipality of Pato Bragado - PR. The collected fruits had predominantly brown epicarps (Dranski et al. 2010). The J. curcas fruits were dried in the shade for 45 days, with no control over temperature and humidity (Zonta et al. 2011) to facilitate manual seed extraction from fruits.

The mass of 1,000 seeds $\left(\mathrm{W}_{1000}\right)$ was determined from eight replicates of 100 seeds, and the seed moisture content (MC) was measured in four replicates of 25 seeds (Brasil 2009).

Germination tests was conducted using four replicates of 25 seeds per provenance, involved in paper towel rolls moistened with 2.5 times their weight of deionized water and maintained at $25.0 \pm 2.0^{\circ} \mathrm{C}$ with a $12 \mathrm{~h}$ photoperiod. Germination was expressed as the percentage of normal seedlings (NS) obtained on the twentieth day after sowing (Brasil 2013). In addition to the germination test, NS were tallied daily to calculate the germination speed index (GSI) (Maguire 1962).

Values obtained from the seed soaking curve were fitted to an equation to determine the point of maximum curvature $(\mathrm{PMC})$. Seed hydration was performed using three sheets of germitest paper moistened with ascorbic acid (750 $\mu \mathrm{mol} \mathrm{L}-1)$ at a volume equal to three times the mass of the dry germitest paper sheets. PMC was determined to be 41 hours after seed hydration initiation.

After the PMC was determined, four replicates of 25 seeds each were hydrated in either a solution of deionized water or ascorbic acid at $750 \mu \mathrm{mol} \mathrm{L}^{-1}$ for $41 \mathrm{~h}$. Seeds were then dried in a circulating air oven at $30^{\circ} \mathrm{C}$ until the initial moisture content of unprimed (control) seeds.

Primed seeds were submitted to accelerated aging, as described in AOSA (1983). Twenty-five seeds were distributed uniformly on top of a plastic screen in Gerbox boxes with $40 \mathrm{~mL}$ of water underneath and kept at constant temperature $\left(41^{\circ} \mathrm{C}\right.$ for $\left.72 \mathrm{~h}\right)$. Seeds were weighed to evaluate moisture content and respiratory activity.

Carbon dioxide concentration was quantified before and after the accelerated aging by placing the seeds in a $250 \mathrm{~mL}$ polypropylene vial. Seeds were added to the vials with no solution and sealed. Rubber tubing, for the capture of $\mathrm{CO}_{2}$, was attached to the vial cap and the vials were maintained at a constant temperature before $\left(25^{\circ} \mathrm{C}\right.$ for $\left.168 \mathrm{~h}\right)$ and after $\left(25^{\circ} \mathrm{C}\right.$ for $24 \mathrm{~h}$ ) the accelerated aging.

Gaseous samples of $2 \mathrm{~mL}$ were extracted with the aid of a Gastight ${ }^{\circ}$ syringe (LT $2.5 \mathrm{~mL}$ and needle KF PT 5 - Hamilton), and injected into the gas chromatograph (Finnigan $9001^{\circ}$, Finnigan/Tremetrics Inc., Austin, TX, USA). The gas chromatograph was equipped with a methanator, flame ionization detector and a Rt-QPLOT ${ }^{\circ}$ capillary column (30 m x $0.53 \mathrm{~mm}$; Restek, Bellefonte, PA, USA). The oven temperature of the detector, the methanator and the injector were $60,250,350$ and $90^{\circ} \mathrm{C}$, respectively. Gas flows of $\mathrm{N}_{2}$, $\mathrm{H}_{2}$ and air were 25,20 and $175 \mathrm{~mL} \mathrm{~min}^{-1}$, respectively, with constant pressure of the carrier gas $\left(\mathrm{N}_{2}\right)$ at 15 psi. The $\mathrm{CO}_{2}$ concentration was determined by comparing the chromatographic peaks of the sample with the standard, and expressed in $\mu \mathrm{mol} \mathrm{CO} \mathrm{g}^{-1} \mathrm{~h}$. At the end of respiratory activity quantification, seed germination percentage and GSI were analyzed again.

The experiment followed a completely randomized design in a factorial arrangement $(3 \times 2)$ formed by three seed priming protocols (control, deionized water and 750 $\mu \mathrm{mol} \mathrm{L}{ }^{-1}$ of ascorbic acid) and two provenances (Janauba and Pedro Juan Caballero) with four replicates of 25 seeds each.

The effect of the treatments was checked for normality, by testing the residual distribution (Shapiro-Wilk test), and variance homogeneity, using Bartlett's test. The results were evaluated by analysis of variance (ANOVA) and Duncan's test, at $5 \%$ probability, with Sigma Plot ${ }^{\circ}$ 12.0 (Systat Software, Inc., San Jose, CA, USA). Pearson's correlation coefficients were calculated between carbon dioxide concentration and seed physiological quality after accelerated aging, at $5 \%$ of probability.

\section{Results}

The weight of J. curcas seeds was determined before and after artificial aging (Tab. 1). Seeds from Pedro Juan Caballero had a higher average weight than the seeds from Janauba, both before and after accelerated aging. 
Table 1. Jatropha curcas seeds weight (g) according to each treatment: before and after accelerated aging, priming treatments (immersion in deionized water or in $750 \mu \mathrm{mol} \mathrm{L} \mathrm{L}^{-1}$ of ascorbic acid [Asc.Ac.]) and provenance (Janauba and Pedro J. Caballero).

\begin{tabular}{|c|c|c|c|c|}
\hline & \multicolumn{2}{|c|}{ Janauba $(\mathbf{g})$} & \multicolumn{2}{c|}{ Pedro J. Caballero (g) } \\
\cline { 2 - 5 } & Before A.A. & After A.A. & Before A.A. & $14.94 \pm 0.54$ \\
\hline Control & $11.81 \pm 0.23^{(1)}$ & $12.84 \pm 0.26$ & $13.79 \pm 0.27$ & $15.08 \pm 0.37$ \\
\hline Water & $11.62 \pm 1.33$ & $12.88 \pm 0.26$ & $13.67 \pm 0.22$ & $14.97 \pm 0.57$ \\
\hline Asc. Ac. & $12.54 \pm 0.91$ & $12.95 \pm 0.56$ & $13.66 \pm 0.27$ & $15.03 \pm 0.64$ \\
\hline Average & $11.99 \pm 0.92$ & $12.89 \pm 0.52$ & $13.71 \pm 0.24$ & After \\
\hline
\end{tabular}

(1) Standard deviation. Wherein: A.A.: accelerated aging; Asc. Ac.: ascorbic acid.

After 41 hours of seed hydration, the PMC reached $42 \%$ of the moisture content (Fig. 1). The PMC indicates that water absorption stops, ending phase I of the seed imbibition curve, with the beginning of phase II, and that the priming process should be maintained. No significant difference was detected in seed moisture content between the two provenances. Radicle protrusion started after $60 \mathrm{~h}$ of seed hydration, without showing a triphasic pattern, while the time required for equalization of seed moisture content (drying period) was $36 \mathrm{~h}$.

Variation in $\mathrm{W}_{1000}, \mathrm{MC}$, NS and GSI prior to the priming treatment is presented in Table 2. Seeds from Pedro Juan Caballero had a higher $W_{1000}$ than the seeds from Janauba. The average values were $635.7 \mathrm{~g}^{-1}$ for $\mathrm{W}_{1000}, 8.0 \%$ for $\mathrm{MC}$, $86.5 \%$ for NS and 3.48 for GSI, for both provenances.

Seed MC differed between the two provenances (Janauba and Pedro Juan Caballero) after seed priming and drying (Tab. 3). Pedro Juan Caballero had a higher average water content for the treatments $(18.7 \%)$. Differences in moisture content of J. curcas seeds after priming and drying was lower than $1 \%$ between provenances and treatments (Tab. 3 ).

For the seeds from Janauba, those primed with ascorbic acid had the highest percentage of NS, followed by priming in water and the control treatment (Tab. 4). For the seeds from Pedro Juan Caballero, those primed with deionized water had the highest percentage of NS, followed by ascorbic acid and the control.

When comparing the results of NS before and after artificial aging, seeds primed with ascorbic acid from Janauba and with deionized water from Pedro Juan Caballero did not exhibit significant differences in the NS (Tab. 4). Therefore, the priming process promoted increased tolerance to stress caused by artificial aging, since unprimed seeds (control) resulted in an average reduction in NS of $17 \%$, while primed seeds had an average reduction of $10 \%$ and $7 \%$, with ascorbic acid and water, respectively, for both provenances.

After accelerated aging, GSI of seeds from Janauba was higher for priming treatments (ascorbic acid or water) compared to the control (Tab. 5). For seeds from Pedro Juan Caballero, priming with water resulted in a higher GSI (3.63) followed by priming with ascorbic acid (3.23) and the control treatment (3.13).

Unprimed seeds (i.e. control treatment) did not differ significantly in germination between provenances. However, seeds from Pedro Juan Caballero primed with water resulted in a higher GSI, while for seeds from Janauba ascorbic acid resulted in a higher GSI.

The results obtained before and after artificial aging were analyzed, and the control treatment showed a reduction in GSI for seeds from Janauba, while the priming treatment with ascorbic acid was not effective at minimizing vigor loss for seeds from Pedro Juan Caballero. In both cases, there was a reduction of $12 \%$ in GSI from pre-artificial aging, indicating that seeds subjected to these conditions require a longer time to stabilize germination.

Respiratory activity of J. curcas seeds prior to accelerated aging differed significantly among treatments from both provenances (Tab. 6).

There was a positive correlation between $\mathrm{CO}_{2}$ concentration and percentage of NS, as well as between $\mathrm{CO}_{2}$ concentration and GSI, for both provenances (Tab. 7). Consequently, an increase in respiratory activity resulted in a higher percentage of NS and that they emerged with greater speed.

For Janauba provenance, seeds primed with ascorbic acid showed a higher concentration of $\mathrm{CO}_{2}$ than those primed with water, followed by the control treatment. Priming also affected seeds from Pedro Juan Caballero, with a higher concentration of $\mathrm{CO}_{2}$ when primed with water after artificial aging.

This trend appears to be associated with seed moisture content (Tab. 3), since the correlations between $\mathrm{CO}_{2}$ concentration and seed water content were 0.99 and 0.95 $(\mathrm{P}<0.0001)$, for seeds from Janauba and Pedro Juan Caballero, respectively.

A difference between the two provenances was detected in accelerated aging versus the control treatment, with control treatment seeds from Janauba exhibiting a 23\% higher respiratory rate than those from Pedro Juan Caballero. The $\mathrm{CO}_{2}$ concentration and GSI of unprimed seeds from both provenances exhibited a negative correlation of $-0.86(\mathrm{P}=0.0156)$, with $\mathrm{CO}_{2}$ concentration increasing after artificial aging while GSI decreased. Thus, the rate of respiration maintenance was higher for less vigorous seeds, as demonstrated by the inversely proportional correlation.

Subsequent to accelerated aging, seeds primed with water or ascorbic acid showed higher respiratory activity independent of provenance compared to unprimed seeds 
(Tab. 6). Seeds from Janauba primed with ascorbic acid exhibited a higher concentration of $\mathrm{CO}_{2}$ than those primed with water. On the other hand, seeds from Pedro Juan Caballero exhibited a higher concentration of $\mathrm{CO}_{2}$ for seeds primed with water than for seeds primed with ascorbic acid.

Seeds from Pedro Juan Caballero responded with an increase in respiratory activity independent of priming treatment, compared to those from Janauba. Despite the difference in respiratory activity between provenances, there was no loss of seed physiological quality. Therefore, the above-mentioned increase was related to seed moisture content, which is higher in seeds from Pedro Juan Caballero after artificial aging (Tab. 3).

\section{Discussion}

Seeds of J. curcas were subjected to priming treatments prior to accelerated aging in order to assess the potential for reduced of seed damage and increased tolerance to oxidative stress, as well as to compare treatments before and after artificial aging. Unprimed seeds exhibited a reduction in physiological quality with accelerated aging, producing few normal seedlings and a decreased germination speed.

According to Parmoon et al. (2013), priming treatment improves germination time, germination percentage, seed vigor and antioxidant activity, while reducing lipid

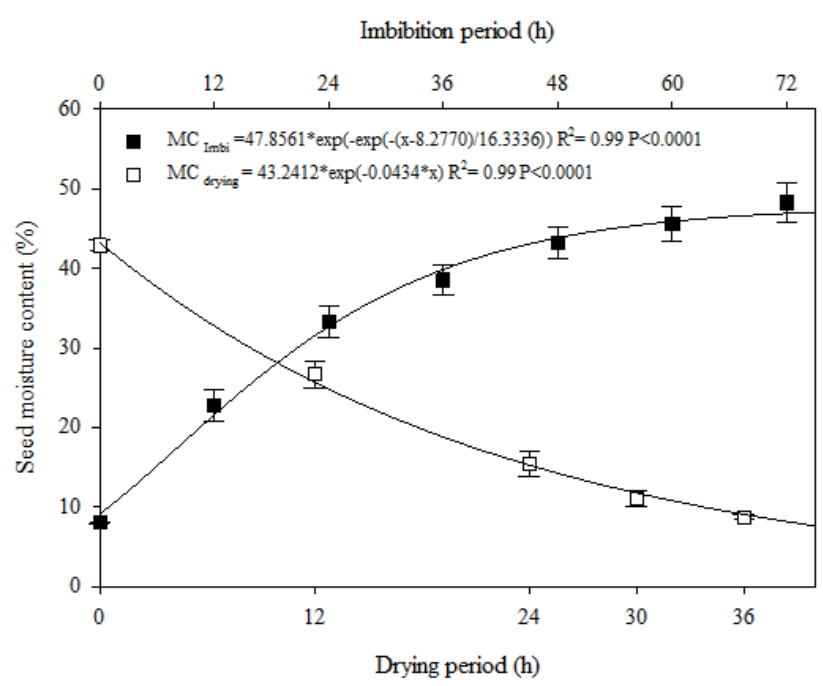

Figure 1. Imbibition period and drying curve of Jatropha curcas seeds.

peroxidation, in seeds of milk thistle (Silybum marianum). Lipid peroxidation begins with the generation of free radicals through autoxidation or enzymatic attack by oxidative enzymes, such as lipoxygenases, present in many seeds (Xin et al. 2014), which is a reaction enhanced by the process of deterioration (Tullio \& Arrigoni 2003).

Table 2. Thousand seed mass $\left(\mathrm{W}_{1000}\right)$, seed moisture content $(\mathrm{MC})$, percentage of normal seedlings (NS) and germination speed index (GSI) in Jatropha curcas seeds from two provenances (Janauba and Pedro J. Caballero).

\begin{tabular}{|c|c|c|c|c|}
\hline \multirow{2}{*}{ Provenance } & \multicolumn{4}{|c|}{ Parameters } \\
\hline & $w_{1000}(g)$ & $M C(\%)$ & NS (\%) & GSI \\
\hline Janauba & $581.53 \pm 38.53^{(1)}$ & $8.0 \pm 0.1$ & $86.0 \pm 2.3$ & $3.36 \pm 0.27$ \\
\hline Pedro J. Caballero & $689.86 \pm 24.66$ & $8.1 \pm 0.2$ & $87.0 \pm 3.8$ & $3.61 \pm 0.28$ \\
\hline
\end{tabular}

(1) Standard deviation

Table 3. Moisture content (MC - \%) in Jatropha curcas seeds before and after accelerated aging (A.A.) as a function of priming (immersion in deionized water or in $750 \mu \mathrm{mol} \mathrm{L}^{-1}$ of ascorbic acid [Asc.Ac.]) and provenance (Janauba and Pedro J. Caballero).

\begin{tabular}{|c|c|c|c|c|c|c|}
\multirow{2}{*}{ Provenance } & \multicolumn{3}{|c|}{ MC (\%) } \\
\cline { 2 - 6 } & \multicolumn{3}{|c|}{ Before A.A. } & \multicolumn{3}{c|}{ After A.A. } \\
\cline { 2 - 7 } & Control & Water & Asc. Ac. & Control & Water & $16.3 \pm 1.2$ \\
\hline Janauba & $7.9 \pm 0.2^{(1)}$ & $8.4 \pm 0.4$ & $8.5 \pm 0.6$ & $17.3 \pm 1.4$ & $18.4 \pm 0.2$ & $19.1 \pm 0.6$ \\
\hline Pedro J. Caballero & $8.0 \pm 0.3$ & $8.9 \pm 0.5$ & $8.8 \pm 0.4$ & $18.4 \pm 0.7$ & 18.7 \\
\hline
\end{tabular}

(1) Standard deviation. Wherein: A.A.: accelerated aging; Asc. Ac.: ascorbic acid.

Table 4. Percentage of normal seedlings (NS) after accelerated aging in Jatropha curcas seeds, as a function of priming (immersion in deionized water or in $750 \mu \mathrm{mol} \mathrm{L}{ }^{-1}$ of ascorbic acid [Asc.Ac.]) and provenance (Janauba and Pedro J. Caballero).

\begin{tabular}{|c|c|c|c|c|}
\hline \multirow{2}{*}{ Provenance } & \multicolumn{4}{|c|}{ NS (\%) } \\
\hline & NSPB & Control & Water & Asc. Ac. \\
\hline Janauba & 86.0 & $72.0 \mathrm{aC}^{(1) \prime \prime}$ & 76.0aB" & $80.0 \mathrm{aA}$ \\
\hline Pedro J. Caballero & 87.0 & $71.0 \mathrm{aC} "$ & $84.0 \mathrm{aA}$ & $75.0 \mathrm{aB} "$ \\
\hline C.V. (\%) & \multicolumn{4}{|c|}{6.5} \\
\hline
\end{tabular}

(1) Data followed by the same letter, uppercase in line and lowercase in column, did not differ statistically (Duncan test, $\mathrm{p}<0.05$ ).

" Significant at $5 \%$ by Duncan test. Wherein: NSPB: normal seedlings percentage before accelerated aging; Asc. Ac.: ascorbic acid. 
Table 5. Germination speed index (GSI) before and after artificial aging in Jatropha curcas seeds as a function of priming (immersion in deionized water or in $750 \mu \mathrm{mol} \mathrm{L}{ }^{-1}$ of ascorbic acid [Asc.Ac.]) and provenance (Janauba and Pedro J. Caballero).

\begin{tabular}{|c|c|c|c|c|}
\hline \multirow{2}{*}{ Provenance } & \multicolumn{4}{|c|}{ GSI } \\
\hline & BA & Control & Water & Asc. Ac. \\
\hline Janauba & 3.36 & $2.97 \mathrm{aB}^{\prime \prime}$ & $3.46 \mathrm{bA}$ & $3.50 \mathrm{aA}$ \\
\hline Pedro J. Caballero & 3.61 & $3.13 \mathrm{a} C^{\prime \prime}$ & 3.63aA & $3.23 \mathrm{bB}$ \\
\hline $\mathrm{CV}(\%)$ & \multicolumn{4}{|c|}{5.8} \\
\hline
\end{tabular}

(1) Data followed by the same letter, uppercase in line and lowercase in the column, did not differ statistically (Duncan test, $\mathrm{p}$ < 0.05). " Significant at $5 \%$ by Duncan test. Wherein: GSI: germination speed index index; BA: Germination speed index before the artificial aging; Asc. Ac.: ascorbic acid.

Table 6. Concentration of $\mathrm{CO}_{2}$ in Jatropha curcas seeds before and after accelerated aging as a function of priming (immersion in deionized water or in $750 \mu \mathrm{mol} \mathrm{L}^{-1}$ of ascorbic acid [Asc.Ac.]) and provenance (Janauba and Pedro J. Caballero).

\begin{tabular}{|c|c|c|c|c|c|c|}
\hline \multirow{3}{*}{ Provenance } & \multicolumn{6}{|c|}{$\mathrm{CO}_{2}\left(\mu \mathrm{mol} \mathrm{g}{ }^{-1} h\right)$} \\
\hline & \multicolumn{3}{|c|}{ Before AA } & \multicolumn{3}{|c|}{ After AA } \\
\hline & Control & Water & Asc. Ac. & Control & Water & Asc. Ac. \\
\hline Janauba & $1.38 \mathrm{a}^{(1)}$ & $1.48 \mathrm{aB}$ & $1.52 \mathrm{aA}$ & $11.03 b c$ & $19.24 \mathrm{bB}$ & $20.68 \mathrm{bA}$ \\
\hline Pedro J. Caballero & $1.12 \mathrm{bC}$ & $1.49 \mathrm{aB}$ & $1.59 \mathrm{aA}$ & $24.90 \mathrm{aC}$ & 49.50aA & $30.14 \mathrm{aB}$ \\
\hline $\mathrm{CV}(\%)$ & \multicolumn{3}{|c|}{10.1} & \multicolumn{3}{|c|}{9.2} \\
\hline
\end{tabular}

(1) Data followed by the same letter, uppercase in line and lowercase in the column, did not differ statistically (Duncan test, $\mathrm{p}$ < 0.05). Wherein: AA: artificial aging; Asc. Ac.: ascorbic acid.

Furthermore, seeds from Janauba primed with ascorbic acid, and from Pedro J. Caballero primed with water, maintained physiological quality even after accelerated aging. For fresh harvested tomato (Lycopersicon esculentum) seeds, osmopriming treatment resulted in improved germination percentage and seedling development, when compared to untreated seeds, and after storage the fresh priming of seeds preserved their enhanced characteristics (Liu et al. 1996).

Partial hydration with water followed by dehydration appears to speed seed germination and uniformity, which is a protocol currently in use commercially for establishing field crops (Goel et al. 2003). Hydropriming was also found to be beneficial for okra (Ablemoschus esculentus) seeds, in both control and salt-stress conditions (Raza et al. 2013), and improved seedling emergence and early growth in wheat (Triticum aestivum) under drought and well-watered conditions (Farooq et al. 2013).

Similar results were found for priming seeds with ascorbic acid. Priming treatments can significantly improve leaf emergence and elongation, chlorophyll content, root length and seedling dry weight, as well as decrease oxidation damage (Farooq et al. 2013), while adding better control of salinity stress (Ghoohestani et al. 2012; Raza et al. 2013).

Ascorbic acid is one of the most important antioxidants for plants and, in combination with other components, protects against oxidative damage resulting from aerobic metabolism, photosynthesis and a range of pollutants (Zhang 2013), besides being active throughout the seed life (Siedow et al. 2010). Consequently, the exogenous application of antioxidants contributes to seed protection against lipid peroxidation (Brilhante et al. 2013).
Table 7. Simple correlation coefficient between carbon dioxide concentration and physiological quality of Jatropha curcas seeds after accelerated aging depending on provenance (Janauba and Pedro J. Caballero).

\begin{tabular}{|c|c|c|}
\hline \multirow{2}{*}{ Provenance } & \multicolumn{2}{|c|}{ Parameters } \\
\cline { 2 - 3 } & NS & GSI \\
\hline Janauba & $0.59^{*}$ & $0.80^{* *}$ \\
\hline Pedro J. Caballero & $0.88^{* *}$ & $0.87^{* *}$ \\
\hline
\end{tabular}

, ${ }^{* *}$ Significant at the $1 \%$ and $5 \%$. Wherein: NS: normal seedlings; GSI: speed germination index.

Seed priming also enhanced tolerance to accelerated aging in J. curcas. With aging, seeds enter a period of rapid decline, during which some lose viability while others germinate normally. In a study of aging of J. curcas seeds, problems with storage and content of seed reserves was reported to be strongly influenced by storage time and temperature (Moncaleano-Escandon et al. 2013). Increased storage time may result in hydrolysis, polymerization and oxidation in seeds of J. curcas, resulting in changes to their chemical properties (Berchmans \& Hirata 2008).

Decreased germination potential with storage is due to the metabolism of the seed and the presence of a high concentration of reducing sugars, so the recommendation is to maintain J. curcas seeds for less than six months (Zhang 2013). Kozlowski (1972) analyzed the effect of oil content in stored seeds and found a range of $35.8 \%$ to $31.1 \%$ after a storage period of four months, with an increase in the content of free fatty acids.

Likewise, accelerated aging has been recognized as a good indicator of the storage capacity of seeds (Shaban 2013). In an experiment with cotton (Gossypium hirsutum) seeds 
submitted to accelerated aging for four days, germination was found to decrease, while deterioration of cell membranes increased progressively with aging (Patanè et al. 2006).

Among the biochemical alterations that occur with seed deterioration are changes in respiration. The metabolism of respiration results in the oxidation of reserves and the production of a large number of intermediates for protoplasm synthesis (proteins, nucleic acids and lipids) and the production of biochemical energy in the form of adenosine triphosphate (Dahal et al. 1996).

Differences in $\mathrm{CO}_{2}$ concentration were observed after seed priming and before accelerated aging in J. curcas, compared to the control treatment. This behavior persisted after seed aging. Seed moisture content also influenced $\mathrm{CO}_{2}$ concentration in seeds from both of the provenances studied. In addition, higher water content was found in seeds from Pedro Juan Caballero, which also expressed the highest $\mathrm{CO}_{2}$ concentration.

Water content seems to influence seed metabolism and respiration rate. In general, respiration and imbibition patterns coincide during seed germination. Respiration may have three stages, with the first corresponding to a rapid increase in $\mathrm{O}_{2}$ consumption and $\mathrm{CO}_{2}$ release. The second stage is characterized by an almost steady rate, while the third stage exhibits a second respiratory burst associated with the mobilization of reserves and seedling growth (Sun et al. 2011; Dahal et al. 1996).

A positive correlation was observed between $\mathrm{CO}_{2}$ concentration, percentage of normal seedlings and GSI in primed seeds, related to germination metabolism in J. curcas. For tomato (Lycopersicon esculentum) seeds, a consistent correlation between germination percentage and respiration was reported in response to water potential, temperature and seed genotype (Dahal et al. 1996). Seed respiration and germination in carrot (Daucus carota), increased in response to seed maturity and hydropriming (Nascimento et al. 2013). Seed priming also enhanced germination in sorghum (Sorghum bicolor) in adverse conditions due to the occurrence of faster water absorption in primed compared to unprimed seeds (Patanè et al. 2009).

Reduction in $\mathrm{CO}_{2}$ concentration resulted in decreased germination speed. This was observed in seeds of the control treatment of both provenances, which can be related to a decrease in seed metabolism due to seed moisture content. The processes involved with maintenance and sustaining mature cells in a viable state creates a high demand for chemical energy, since the use of energy by maintenance respiration includes the synthesis of proteins and mRNAs, with higher levels of energy released by organisms in an advanced state of deterioration (Siedow et al. 2010).

Additionally, high values of the respiratory quotient are often found in deteriorated seeds, both as a result of increased $\mathrm{CO}_{2}$ release and decreased $\mathrm{O}_{2}$ consumption. However, the respiration pattern of damaged seeds can be complex and variable. There having been reports of both increased and decreased oxygen uptake. Such changes sometimes precede, or accompany, the loss of germination capacity (Bewley et al. 2013).

The data reported in this paper demonstrated that priming J. curcas seeds with water or ascorbic acid assists in reducing damage from accelerated aging, thereby increasing the number of normal seedlings and GSI. Moreover, decline in seed physiological potential after accelerated aging is linked to the reduced respiratory activity of aged seeds (lower $\mathrm{CO}_{2}$ concentration).

\section{Conclusions}

Hydropriming resulted in a high percentage of normal seedlings, a high germination speed index (GSI) and increased respiratory activity for J. curcas seeds from Pedro Juan Caballero, while priming with ascorbic acid enhanced seeds from Janauba. Seeds from Pedro Juan Caballero showed greater respiratory activity independent of priming treatment. The reduction in respiratory activity of J. curcas seeds can be related to seed moisture content.

\section{Acknowledgements}

We acknowledge the Coordenação de Aperfeiçoamento de Pessoal de Nível Superior (CAPES) for providing financial support and a research grant.

\section{References}

Abhilash PC, Srivastava P, Jamil S, Singh N. 2011. Revisited Jatropha curcas as an oil plant of multiple benefits: critical research needs and prospects for the future. Environmental Science and Pollution Research 18: 127-131.

AOSA - Association of Official Seed Analysis. 1983. Seed vigor testing handbook. Contribution 32. East Lansing, AOSA.

Berchmans HJ, Hirata S. 2008. Biodiesel production from crude Jatropha curcas L. seed oil with a high content of free fatty acids. Bioresource Technology 99: 1716-1721.

Bewley JD, Bradford K, Hilhorst H, Nonogaki H. 2013. Seeds: physiology of development, germination and dormancy. New York, Springer.

Brasil. 2009. Regras para análise de sementes. Brasília, Mapa/ACS.

Brasil. 2013. Instruções para análise de sementes de espécies florestais. Brasília, Mapa.

Brilhante JCA, Oliveira AB, Silva JW, Enéas Filho J. 2013. Ação do ácido ascórbico exógeno na qualidade fisiológica de sementes de feijão de corda envelhecidas artificialmente. Semina Ciências Agrárias 34: 985-994.

Costa JL, Silva ALL, Bier MCJ, et al. 2015. Callus growth kinetics of physic nut (Jatropha curcas L.) and content of fatty acids from crude oil obtained in vitro. Brazilian Archives of Biology and Technology 176: 892-902.

Dahal P, Kim NS, Bradford KJ. 1996. Respiration and germination rates of tomato seeds at suboptimal temperatures and reduced water potentials. Journal of Experimental Botany 47: 941-947.

Dranski JAL, Pinto Júnior AS, Steiner F, et al. 2010. Physiological maturity of seeds and colorimetry of fruits of Jatropha curcas L. Revista Brasileira de Sementes 32: 158-165.

Farooq M, Irfan M, Aziz T, Ahmad I, Cheema SA. 2013. Seed priming with ascorbic acid improves drought resistance of wheat. Journal of Agronomy and Crop Science 199:12-22. 


\section{Physiological quality and seed respiration of primed Jatropha curcas seeds}

Ghoohestani A, Gheisary H, Zahedi SM, Dolatkhahi A. 2012. Effect of seed priming of tomato with salicylic acid, ascorbic acid and hydrogen peroxide on germination and plantlet growth in saline conditions. International Journal of Agronomy and Plant Production 3: 700-704.

Goel A, Goel AK, Sheoran IS. 2003. Changes in oxidative stress enzymes during artificial ageing in cotton (Gossypium hirsutum L.) seeds. Journal of Plant Physiology 160: 1093-1100.

Gui MM, Lee KT, Bhatia S. 2008. Feasibility of edible oil vs. non-edible oil vs. waste edible oil as biodiesel feedstock. Energy 33: 1646-1653.

Khan TMY, Atabani AE, Badruddin IA, Badarudin A, Khayoon MS, Triwahyono S. 2014. Recent scenario and technologies to utilize non-edible oils for biodiesel production. Renewable and Sustainable Energy Reviews 37: 840-851.

Koh MY, Ghazi TIM. 2011. A review of biodiesel production from Jatropha curcas L. oil. Renewable \& Sustainable Energy Reviews 15: 2240-2251.

Kozlowski TT. 1972. Seed biology: Germination control, metabolism, and pathology. 1st. edn. New York, Academic Press.

Liu Y, Bino RJ, Burg WJ, Groot SPC, Hilhorst HWM. 1996. Effects of osmotic priming on dormancy and storability of tomato (Lycopersicon esculentum Mill.) seeds. Seed Science Research 6: 49-55.

Maguire JD. 1962. Speed of germination-aid in selection and evaluation for seedling emergence and vigor. Crop Science 2: 176-177.

Marcos Filho J. 2015. Fisiologia de sementes de plantas cultivadas. 2nd. edn. Piracicaba, FEALQ

Moncaleano-Escandon J, Silva BCF, Silva SRR, Granja JAA, Alves MCJL, Pompelli MF. 2013. Germination responses of Jatropha curcas L. seeds to storage and aging. Industrial Crops and Products 44: 684-690.

Nascimento WM, Huber DJ, Cantliffe DJ. 2013. Carrot seed germination and respiration at high temperature in response to seed maturity and priming. Seed Science and Technology 41: 164-169.

Parmoon G, Ebadi A, Jahanbakhsh S, Davari M. 2013. The effect of seed priming and accelerated aging on germination and physiochemical changes in milk thistle (Silybum marianum). Notulae Scientia Biologicae 5: 204-211.

Patanè C, Cavallaro V, Avola G, D'Agosta G. 2006. Seed respiration of sorghum [Sorghum bicolor (L.) Moench] during germination as affected by temperature and osmoconditioning. Seed Science Research 14: 251-260.

Patanè C, Cavallaro V, Cosentino SL. 2009. Germination and radicle growth in unprimed and primed seeds of sweet sorghum as affected by reduced water potential in $\mathrm{NaCl}$ at different temperatures. Industrial Crops and Products 30: 1-8.

Raza SH, Shafiq F, Chaudhary M, Khan I. 2013. Seed invigoration with water, ascorbic and salicylic acid stimulates development and biochemical characters of okra (Abelmoschus esculentus) under normal and saline conditions. International Journal of Agriculture \& Biology 15: 486-492.

Shaban M. 2013. Review on physiological aspects of seed deterioration. International Journal of Agriculture and Crop Sciences 6: 627-631.

Siedow JN, Moller IM, Rasmusson A. 2010. Does respiration reduce crop yields? In: Taiz L, Zeiger E. (ed.) A Companion to plant physiology. 5th. edn. Sunderland, Sinauer Associates. p. 7-11.

Sun H, Li L, Wang X, Wu S, Wang X. 2011. Ascorbate-glutathione cycle of mitochondria in osmoprimed soybean cotyledons in response to imbibitional chilling injury. Journal of Plant Physiology 168: 226-232.

Tullio MC, Arrigoni O. 2003. The ascorbic acid system in seeds: to protect and to serve. Seed Science Research 13: 249-260.

Xin X, Tian Q, Yin G, et al. 2014. Reduced mitochondrial and ascorbateglutathione activity after artificial ageing in soybean seed. Journal of Plant Physiology 171: 140-147.

Zhang Y. 2013. Ascorbic acid in plants: biosynthesis, regulation and enhancement. New York, Springer-Verlag.

Zhao G, Zhong T. 2012. Improving the assessment method of seed vigor in Cunninghamia lanceolata and Pinus massoniana based on oxygen sensing technology. Journal of Forestry Research 23: 95-101.

Zheng C, Jiang D, Liub F, et al. 2009. Exogenous nitric oxide improves seed germination in wheat against mitochondrial oxidative damage induced by high salinity. Environmental and Experimental Botany 67: 222-227.

Zonta JB, Araujo EF, Araujo RF, Dias LAS. 2011. Diferentes tipos de secagem: efeitos na qualidade fisiológica de sementes de pinhãomanso. Revista Brasileira de Sementes 33: 721-731. 